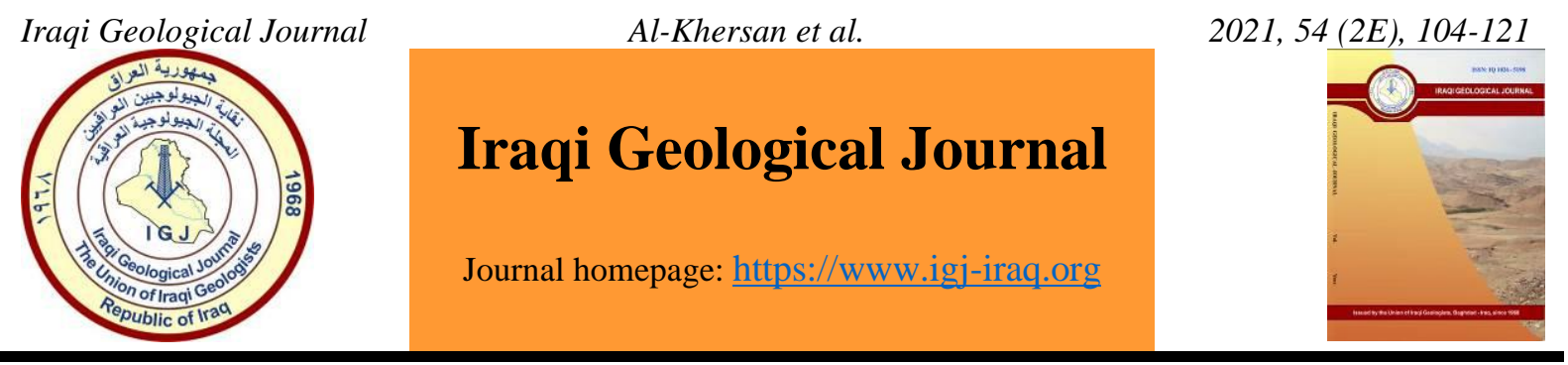

\title{
Integrated Ground Penetrating Radar and Electrical Resistivity Study to Explore Such Basrah Low Resistivity Soils for Engineering Purposes, Southern Iraq
}

\author{
Emad H. Al-Khersan ${ }^{1, *}$, Basim R. Hijab ${ }^{2}$ and Israa A. Al-Khazali ${ }^{3}$ \\ Department of Oil and Gas Engineering, Basrah University for Oil and Gas, Basrah, Iraq \\ Department of Geology, College of Science, University of Baghdad, Baghdad, Iraq \\ Department of Subsurface Geology, New Well Delivery, Basrah Oil Company, Rumaila, Basrah, Iraq \\ * Correspondence: emad.alkhersan@buog.edu.iq
}

Received: 27 June 2021; Accepted: 25 August 2021; Published: 30 November 2021

\begin{abstract}
A total of 45 ground penetrating radar profiles have been conducted in Basrah City, Southern Iraq, to detect buried utilities in such soils which have not been tested before. This study tries to explore how much this technique can be useful for Basrah low resistivity soils during arid and humid seasons. In Basrah University Campus (silty clay soil) and Basrah Sport City (silty sand soil), 37 and 8 ground penetrating radar profiles were achieved inside these locations respectively. Vertical electrical sounding (Schlumberger array) and electrical profiling (Wenner array) were also used in compatibility with radar surveys side by side in all sites. Here, radargrams do not reveal much more details about the subsurface conditions because of the moisture content and soil characterizations. The actual penetrating depth of 250 and $500 \mathrm{MHz}$ antennas are limited to 1.4 and $0.4 \mathrm{~m}$ respectively due to the soil total dissolved solids of about $6790 \mathrm{ppm}$. The tests suggest that the $250 \mathrm{MHz}$ antenna is somewhat better than the $500 \mathrm{MHz}$ one for detecting the shapes and depths of the buried bodies in silty clay soils during rainy or even arid periods. In Basrah Sport City $(500 \mathrm{MHz})$ antenna, the radargram wave signals are not good for more than $2.5 \mathrm{~m}$ depth, and this antenna, rather than the $250 \mathrm{MHZ}$ one is suitable for silty sand soil type.
\end{abstract}

Keywords: Objects; Basrah; Trenches; Utilities; Soil

\section{Introduction}

Geophysical methods have an important role in engineering geology, particularly for infrastructures. They are non-destructive testing methods for detecting subsurface weak zones, dynamic elastic moduli, earthquake hazard design and many other targets. Re-building of Iraq, particularly the Basrah area, has a real need for ground penetrating radar (GPR) method to monitor subsurface utilities. However, in the past few decades, the south and west of Basrah were greatly damaged due to several circumstances that caused soil settlements, the matter that directly collapse the subsurface utilities (pipes, cables and channels). For such cases, the GPR can be used as a power geophysical tool to detect these subsurface utilities, but the application of this method has several limitations, particularly for Basrah soil characterizations. 
The study area lies in Basrah Governorate, bounded by longitude $47^{\circ} 44^{\prime} 54.87$ " $-47^{\circ} 64^{\prime} 33.9^{\prime \prime}$ and latitude $30^{\circ} 34^{\prime} 01.0 "-30^{\circ} 58^{\prime} 23.7^{\prime \prime}$. The studied area is flat, empty from vegetations and does not contain any construction with ground level of few meters above the main sea level (Fig. 1). The Dibdibba Formation at the southern part of Iraq (Basrah Governorate) is vertically divided into two aquifers; the unconfined aquifer with saturated brackish water and thickness interval ranging from $10 \mathrm{~m}$ to $20 \mathrm{~m}$; and the lower confined (brackish-saline) aquifer (Haddad and Hawa, 1979). Khorshid et al., (2006) used the seismic refraction technique in 23/2/2005 to delineate ground water level in the area, and found it about $2.3 \mathrm{~m}$ below ground surface. Abed et al. (2021) also used the seismic and electrical resistivity methods and described them as a most common surface technique.

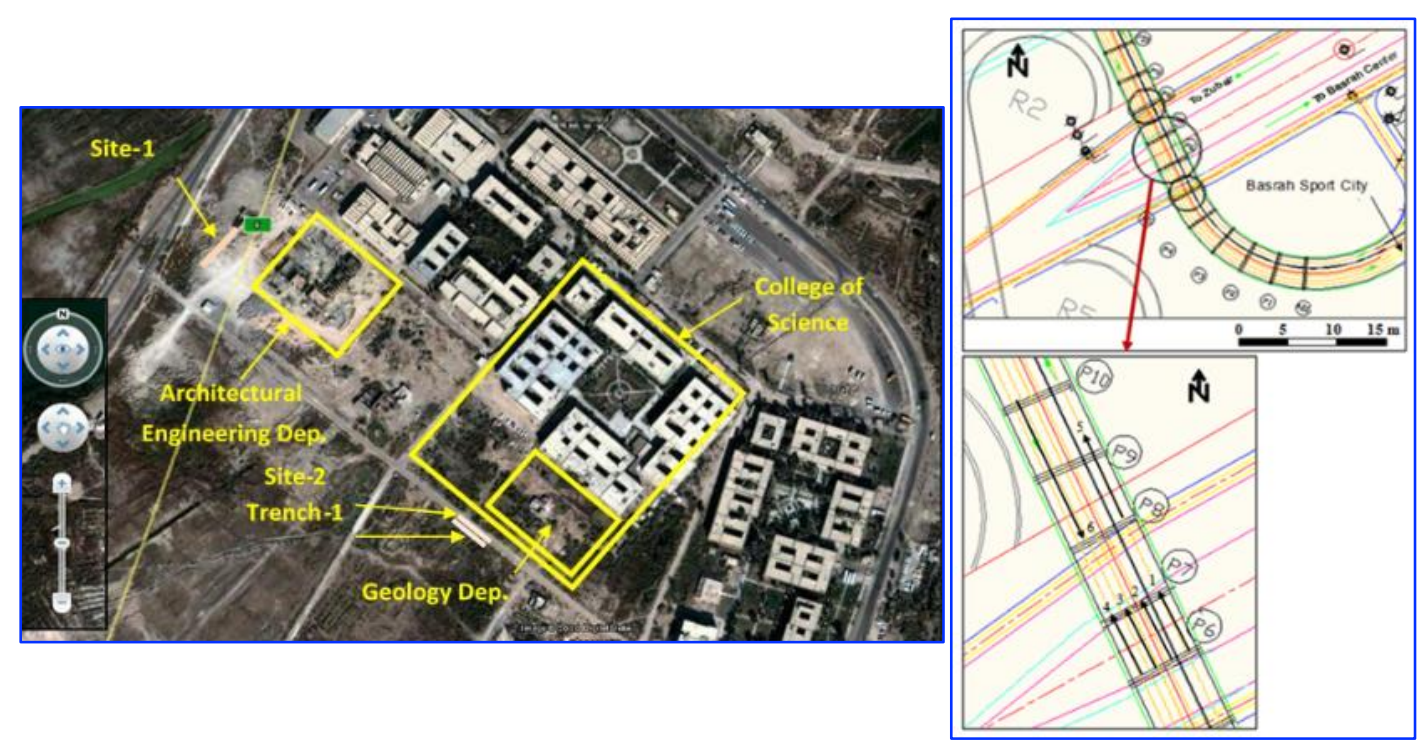

Fig. 1. Locations of the study area including the selected sites at Basrah University Campus (left) and Basrah Sport City (right)

The importance of this study is to investigate the possibility of using GPR in different types of Basrah soil. It is a new technique that was applied successfully in many places, but has not been tested for Basrah soil special conditions. No GPR studies have been conducted in the Basrah area. Therefore, this study can be considered the first one. After the second Gulf war in 1993, the United Nations sent delegates Iraq to dispose of its weapons. The delegates used several detecting techniques, including GPR that is portable by helicopters. Al-Khersan (2012A) achieved seven vertical electrical sounding (VES) stations and 32 GPR profiles in an industrial site, located in Southern Iraq. Geotechnical and hydrogeological investigations were used as additional tools to detect cavities and weak zones as well as the resulting channels underlying the considered site. Several pronounced anomalies of high resistivity zones and radargrams that indicate the existence and extension of cavities were presented and analyzed. This article aims to test the applications of the GPR method to explore the subsurface utilities at Basrah University Campus and Basrah Sport City.

\section{Geologic Setting}

The study area is composed of alluvial and flood plain deposits that represent the Dibdibba Formation (quaternary deposits). The engineering arrondissement staff of Basrah University drilled two boreholes, BH.1 and BH.2 inside the area understudy in 1997 and 2011 with total depths of 26 m. The stratigraphic column shows that the underlying layers mainly consist of clay, clayey silt, sand and silty sand (Fig. 2). 


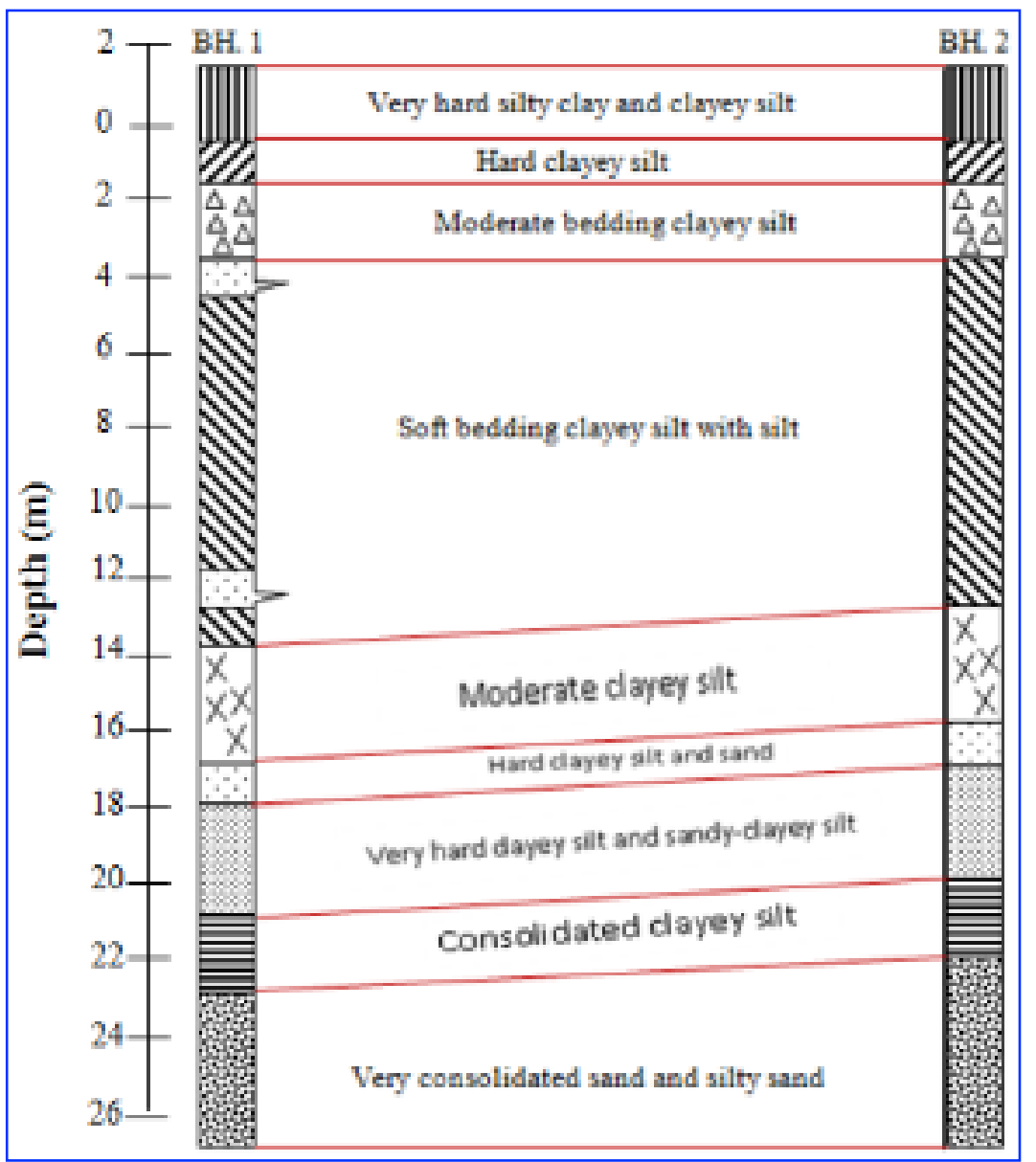

Fig. 2. Stratigraphic column for both BH.1 and BH.2 inside Basrah University Campus

\section{Materials and Methods}

In this study, GPR and Tetrameter Signal Averaging System (SAS-4000) were used. In many cases, the standard operating parameters setting of GPR (velocity, sampling frequency, point interval, time windows and antenna separation) does not work properly, because the site characterizations are the almost important factors that state the values of these parameters. Sampling frequency was set to approximately 10 times the antenna frequency (equals to $2616 \mathrm{MHz}$ ), but the operator can do his settings and change it according to his experience. Generally, the attenuation occurred by earth filtration is considered as the main reason to the reduction of the signal amplitude values that represent the higher return times. Thus, several types of filters can be processed and applied during the GPR fieldwork measurement, however, using these filters is not safe on the present collected raw data. This step is performed to check the quality of the collected raw data (radargrams) in the field, and observe whether these radargrams contain the anomalies of the targets. This makes GPR more useful (Telford et al., 1990). The field work was conducted during many periods within one year starting on 11/10/2010 and ending on 25/10/2011. The main reason for this long period is to study the behavior of GPR responses related to depth penetration for Basrah soil during different weather conditions (arid and humid seasons). The study was conducted at two locations within Basrah City, namely, Basrah University Campus and Basrah Sport City. All the detailed information about the GPR profiles and several electrical resistivity surveys are mentioned in (Table 1). 
Table. 1. Detailed field work in the studied area during this research

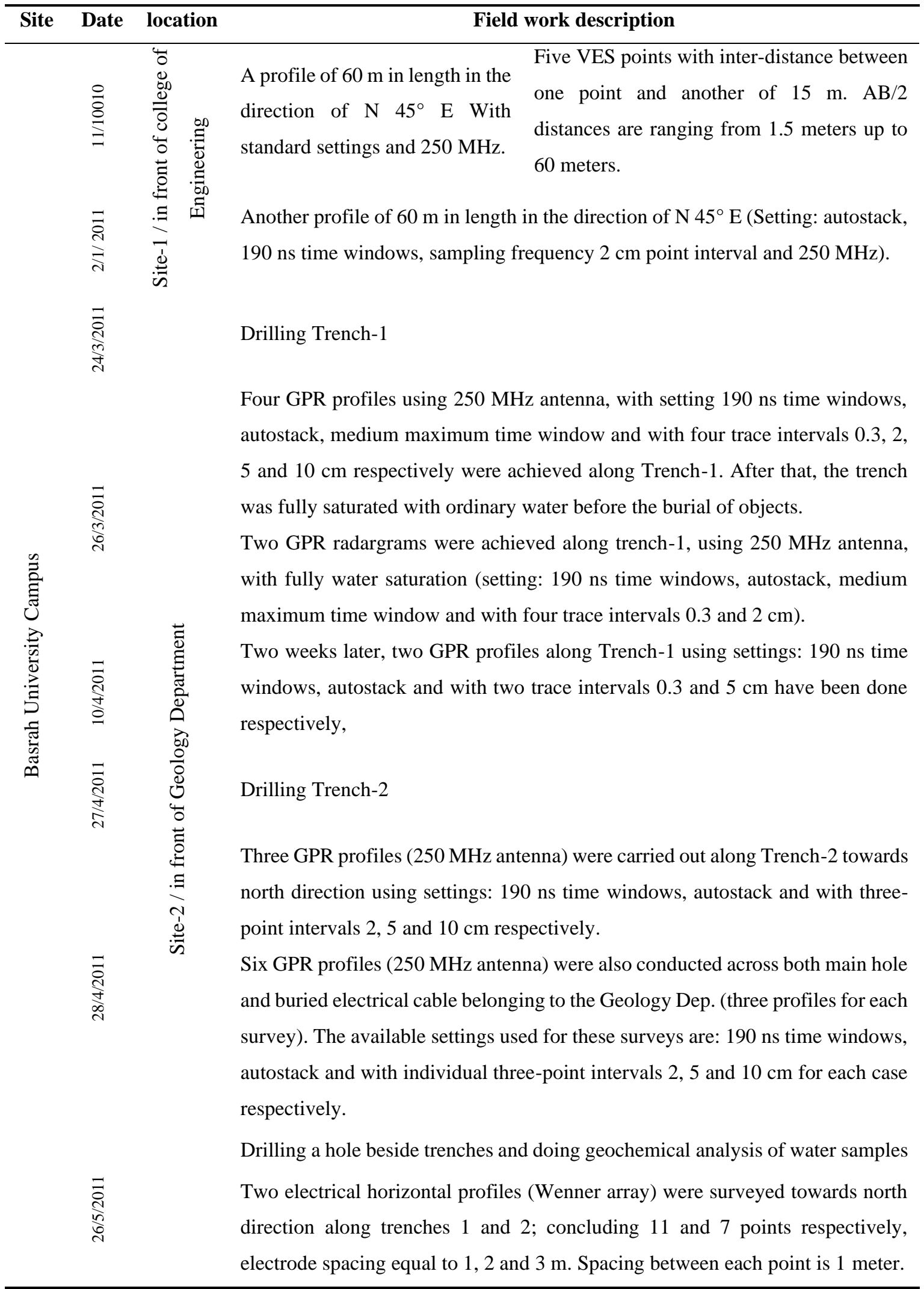


Continued ....

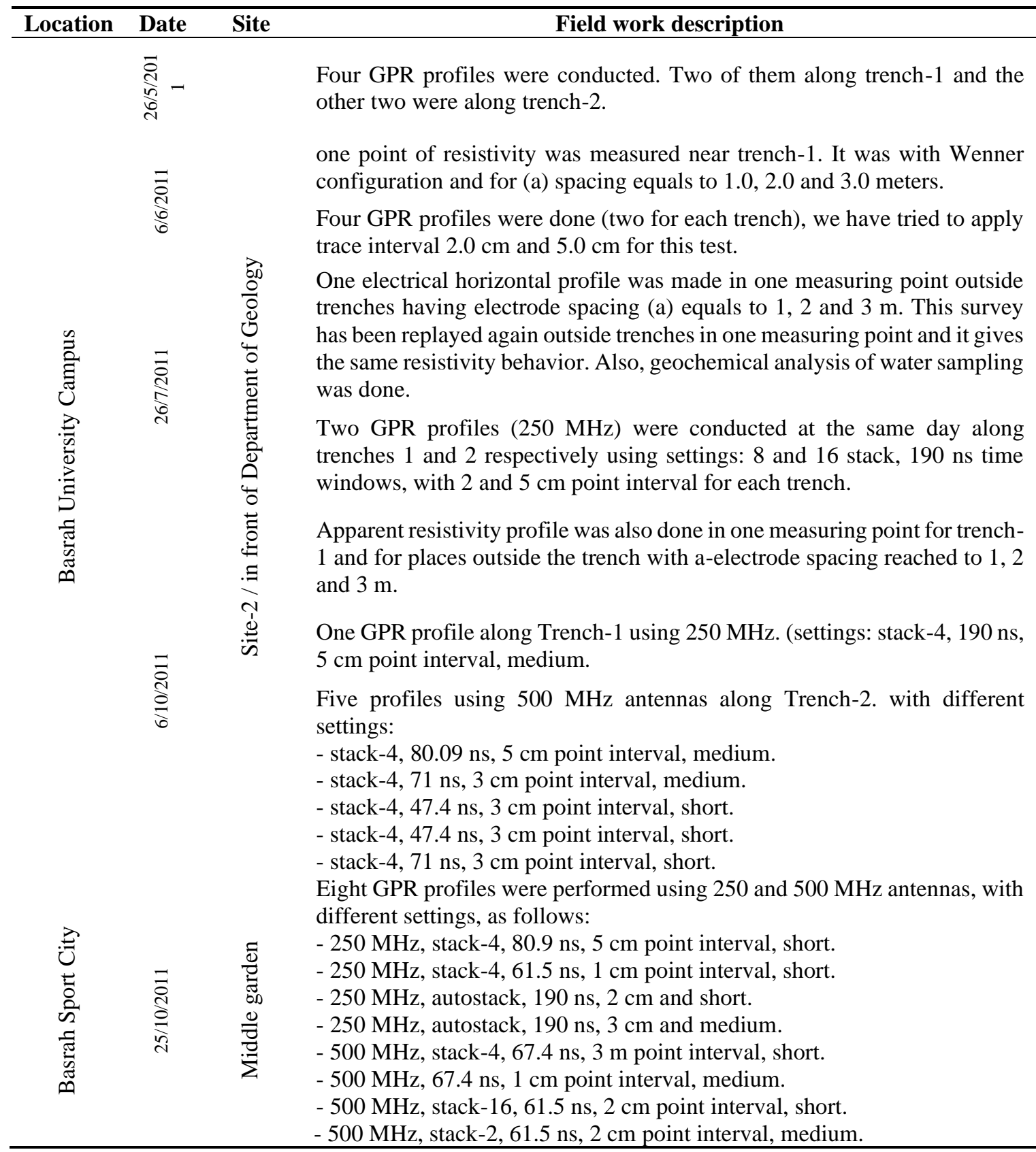

Sites 1 and 2 were selected inside the Basrah University Campus. Consideration both sites should be easily accessible during the field survey, and far from all artificial effects that could interfere with the response readings. The weather is moderate-low temperature, and the soil is semi dry to wet. The soil at this location mainly consists of silty clay to clay. Site-1 was considered a first test that helped in identifying the behavior of GPR response. Therefore, VES (Schlumberger array) was conducted in 11/10/2010 along the $60 \mathrm{~m}$ profile at five measuring points in front of the Architectural Engineering Department. In this survey, the resistivity values were ranged between $0.410-1.414$ ohm.m. Thus, GPR using standard settings was used to carry out along the same profile that was surveyed by the VES above. Our main task in this step was to compare the VES and GPR results. According to Al-Khersan (2012B), special care was taken to avoid artificial high-frequency noise that could deteriorate the radar signal. In 24/3/2011, a Trench-1 (7.5 m length, $0.9 \mathrm{~m}$ width and $1.5 \mathrm{~m}$ depth) was drilled at Site-1 towards the north direction using a special vehicle; however, six different objects were firstly prepared and buried 
inside this trench. These objects were: plastic pipe filled with fresh water, plastic pipe filled with saline water, empty plastic pipe, empty iron pipe (all pipes have 10-inch diameter), two artificial rock blocks and empty wooden box of $0.5 \times 0.5 \times 0.7 \mathrm{~m}$ dimensions. The distance between each object was $1 \mathrm{~m}$. In 27/4/2011, another trench was drilled parallel to Trench-1 named "Trench-2" with a distance spacing equal to $2 \mathrm{~m}$. The dimensions of this trench were: $7.5 \mathrm{~m}$ length, $0.9 \mathrm{~m}$ width and $1 \mathrm{~m}$ depth. Again, another six different objects were buried inside this trench exactly similar to the previous work with several arrangements. These objects were: empty plastic pipe, plastic pipe filled with fresh water, plastic pipe filled with saline water, empty iron pipe (all pipes had a 4-inch diameter), electrical cable $(2.5 \mathrm{~mm}$ diameter $)$ and finally, empty wooden box with $(0.5 \times 0.5 \times 0.7) \mathrm{m}$ dimensions. Moreover, the distance between each object was $1 \mathrm{~m}$ (Fig. 3).

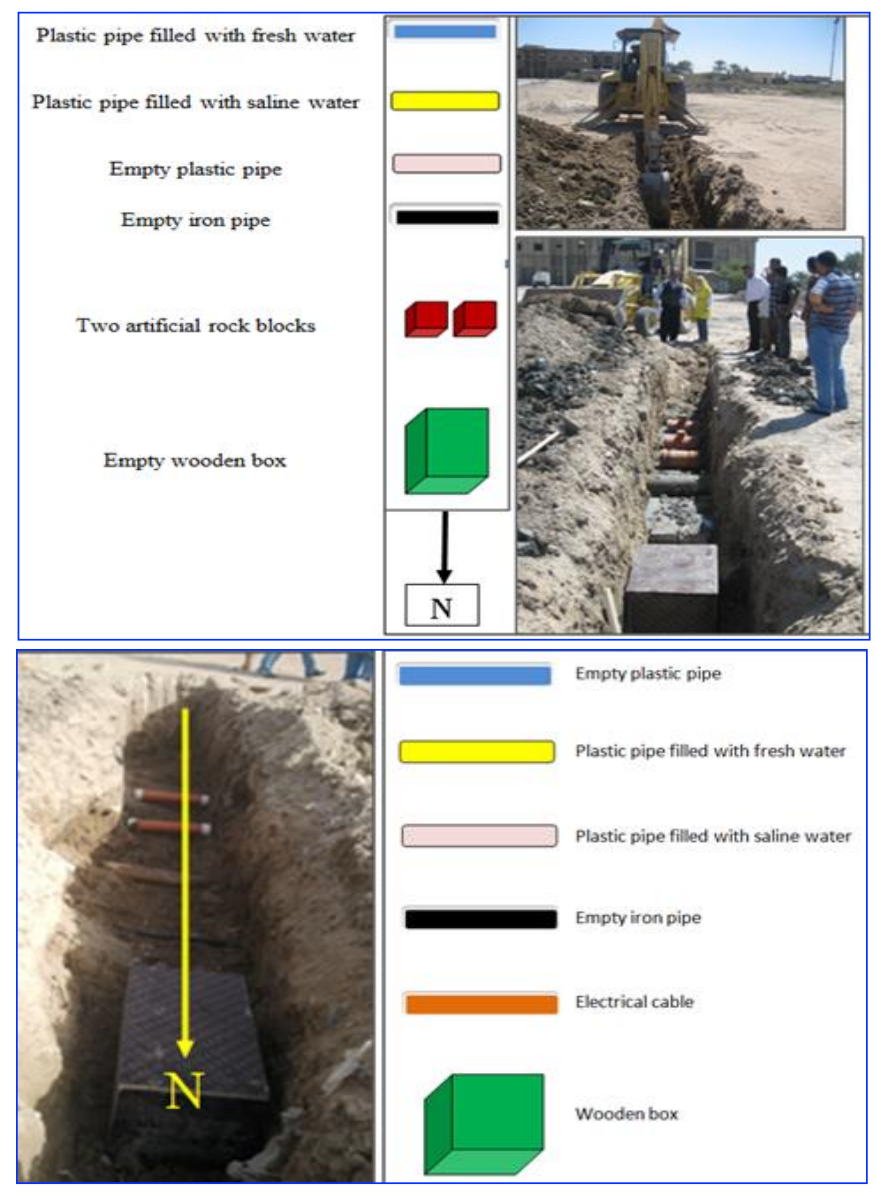

Fig. 3. Trench-1 (above) and Trench-2 (below) with simple sketch of the buried objects

All GPR profiles done along Trench-1 started from the pipe that was filled with fresh water (blue color) and ended at the trench boundary near the wooden box (green color), and were surveyed towards the north direction. Several difficulties related to the nature of drilling and water table appearance were encountered during this work. In spite of this, eight GPR profiles were conducted in this trench during $26 / 3$ to $10 / 4 / 2011$, using different settings to explore the subsurface soil and finding utilities. In 28/4/2011 nine GPR profiles were done along Trench-2 and across mainhole and buried electrical cable belonging to the Geology Department. In 2/5/2011, two electrical horizontal profiles (Wenner array) were surveyed towards the north direction parallel to Trenches 1 and 2 . The electrical apparent resistivity readings of these surveys are still low and ranged between 0.833 to 2.847 ohm.m. In 26/5/2011, a hole with 4-inch diameter and $2 \mathrm{~m}$ depth were drilled beside the trenches, using a manual drilling machine (Auger). Soil and water samples were collected to measure Total Dissolved Solids (TDS); and identify 
soil types. On this basis, TDS was measured on the same day and found to be equal to $6790 \mathrm{ppm}$. Moreover, silty clay and clayey silt were mainly noticed. In 25/7/2011, another electrical horizontal profile was made at one measuring point outside the trenches with different electrode spacings equal to 1,2 and $3 \mathrm{~m}$, and the obtained apparent resistivity readings were $0.722,1.364$ and 0.720 Ohm.m respectively (high electrical conductivity). However, TDS was measured again and was found to be $9350 \mathrm{ppm}$. The geochemical analysis of water sampling clearly showed that brackish-saline groundwater and disposal solid wastes exist. Four GPR profiles $(250 \mathrm{MHz})$ were conducted on the same day along Trenches 1 and 2.

An area inside the Basrah was selected as a case study named "Basrah Sport City" to obtain an accurate GPR response via Basrah soil type. The region is located outside Basrah center towards Zubair District. Lithologically, it consists of alluvial and flood plain deposits representing the Dibdibba Formation. It is composed of sand and silty sand soil with water table reaching about $2.5 \mathrm{~m}$. The contracted company named "Anwar Soura General Cont. Ltd." want to build a circular bridge across the Basrah-Zubair highway that connect the Sport City with the highway towards the Basrah Airport. Therefore, the GPR technique was used to detect buried water and/or oil pipes, electrical cables and the important optical cable passing through the middle garden inside the Basrah-Zubair highway. Based on these objective demands, eight GPR profiles were performed in 25/10/2011 inside the middle garden (in front of the sport city) using 250 and $500 \mathrm{MHz}$ antennas, with different settings.

Two-dimensions radargrams were plotted using Rad Explorer Version 1.4 software to identify the quality of the field data without applying any type of processing such as: data editing, processing filters, dc-removal filter, time-zero adjustment filter, amplitude correction filter (time-gain filter), bandpass filter, background removal filter and stolt $\mathrm{f}-\mathrm{k}$ migration filters.

\section{Results and Discussion}

The primary aim of GPR radargram interpretation in this study was to determine the two ways of travel time from the different types of boundaries such as artifacts or any possible geologic structures. Moreover, the resistivity survey was carried out to identify the water table and the resistivity of the subsurface soil layers because GPR mainly depends on the resistivity of the soil. In Site-1, the considerable five VES along the test profile were interpreted by applying qualitative and quantitative techniques, using IPI2Win Russian software. The first look at the plotted electrical field curves revealed the existence of four soil layers (Orellana and Mooney, 1966), (Compagnie General De Geophysique, 1963). The electrical resistivities and thicknesses for these layers were determined by using the EBERT interpretation method (Table. 4).

Table. 4. Electrical resistivity values, thicknesses and curves types determined for the selected VES points of Site-1

\begin{tabular}{|c|c|c|c|c|c|c|c|c|c|}
\hline \multirow[t]{3}{*}{$\begin{array}{l}\text { VES } \\
\text { Point }\end{array}$} & \multicolumn{8}{|c|}{ Electrical resistivity $(\rho)$ in $(\mathrm{Ohm} . \mathrm{m})$ and thickness $(\mathrm{h})$ in meter } & \multirow[t]{2}{*}{$\begin{array}{c}\text { Curve } \\
\text { Type }\end{array}$} \\
\hline & \multicolumn{2}{|c|}{ Layer 1} & \multicolumn{2}{|c|}{ Layer 2} & \multicolumn{2}{|c|}{ Layer 3} & \multicolumn{2}{|c|}{ Layer 4} & \\
\hline & $\rho_{1}$ & $\mathrm{~h}_{1}$ & $\rho_{2}$ & $\mathrm{~h}_{2}$ & $\rho_{3}$ & $\mathrm{~h}_{3}$ & $\rho_{4}$ & $\mathrm{~h}_{4}$ & \\
\hline 1 & 0.7043 & 0.9 & 1.654 & 1.263 & 0.414 & 10.33 & 0.5621 & - & KK \\
\hline 2 & 0.6626 & 0.8528 & 1.165 & 1.408 & 0.3567 & 29.99 & 3.186 & - & KK \\
\hline 3 & 1.136 & 1.077 & 0.7058 & 3.571 & 0.3769 & 16.07 & 0.8108 & - & QK \\
\hline 4 & 1.51 & 0.964 & 0.838 & 2.86 & 0.378 & 8.33 & 0.618 & - & QK \\
\hline 5 & 1.492 & 0.9644 & 0.8391 & 2.629 & 0.4022 & 9.589 & 0.597 & - & QK \\
\hline
\end{tabular}

The above results show that the depth of water table varies from $0.85 \mathrm{~m}$ to $1.01 \mathrm{~m}$. In general, the resistivity data reflects the high salty soil of the study area. The second, third and fourth layers could 
reflect soil variations between clay and silt. A geoelectrical section of the apparent resistivity values were plotted using the same software (Fig. 4). AB/2 spacing ranged between 1.5-60 m.

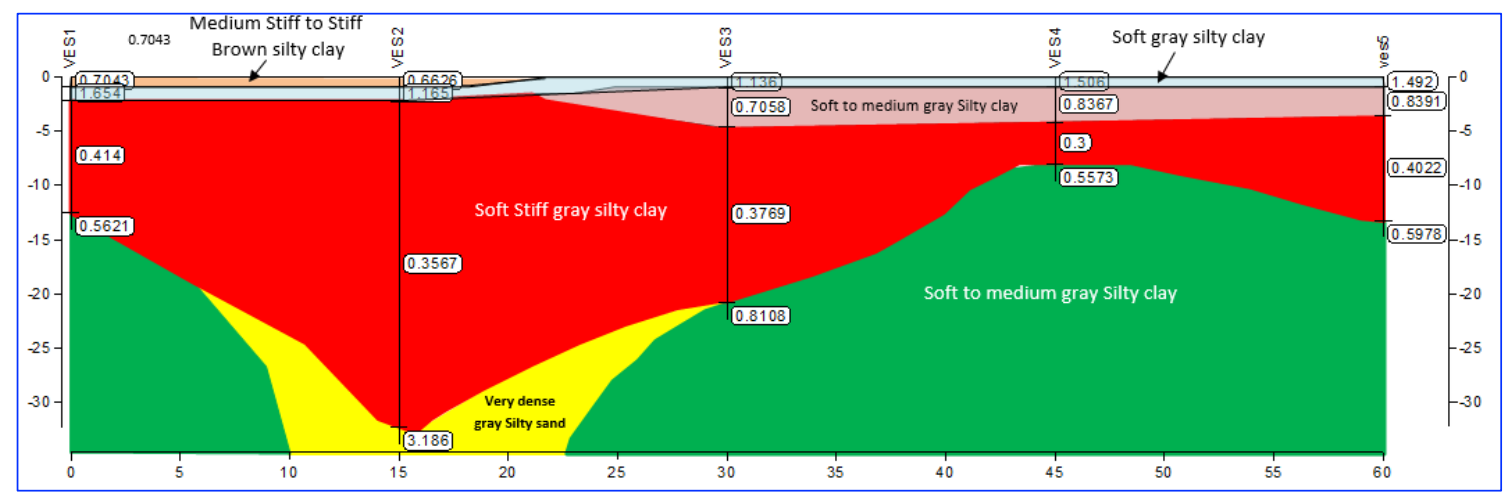

Fig. 4. The geoelectrical section of the tested profile

These sections showed gradual variations in the apparent resistivity distribution. The soil type and its water content, in addition to the increment of current electrode layout, were the extremely reasons for these variations. Therefore, no or less response was noticed in its GPR radargram. This figure shows the vertical and horizontal variations in resistivity values at $A B / 2$ spacing ranging between $1.5-10 \mathrm{~m}$. Moreover, VES points 1and 2 are points of low resistivities (between 0.6-0.7 Ohm.m) at these spacing (curves type is $\mathrm{KK}$ ). For $\mathrm{AB} / 2$ spacing greater than $10 \mathrm{~m}$, a substantial increase in resistivity values was observed. Otherwise, the rest of the VES points (3, 4 and 5) revealed high resistivities at the beginning of electrode spreading (curves type is QK). The resistivity contour closure (more than $3.18 \mathrm{Ohm} . \mathrm{m}$ ) observed at $15 \mathrm{~m}$ from the beginning of the layout (black area and its surroundings) may result from the existence of soft stiff grey silty clay deposits. It represents the artificial channel inside Basrah University that was used previously for landfill purposes and was a burial after that. Moreover, $A B / 2$ spacing ranging between 20-60 m, has low resistivities between 0.3-0.4 Ohm.m due to groundwater saturation. The geoelectrical section included five VES points in which manual quantitative interpretation was first done using auxiliary point of partial curve matching method depending on (Mahmood, 1997) and (Gómez-Ortiz el al., 2010). Based on these facts and because of higher electrical conductivity values at such areas, especially beneath VES 1 and 2, the electromagnetic signals might be attenuated at these levels; therefore, the water table was hardly identified in the GPR radargram. The average water level was calculated as a 1.4-meter depth. The GPR method was quite limited when the resistivity was less than 20.0 Ohm.m. Accordingly, the above resistivity results suggest that this low resistivity soil is not suitable for GPR. Thus, this study will try to explore how much the GPR technique can be useful for such Basrah low resistivity soil.

In Site-2, 35 GPR profiles were conducted along Trenches 1 and 2 with the surroundings to ascertain several tasks related to this research. Each profile was conducted twice or more using different GPR settings. Therefore, only one radargram (the better and clear) was considered and interpreted here. Otherwise, the remaining radargrams almost had difficulty recognizing the shape of the objects. The image of an object in the radar sections did not correspond to its real buried geometrical representation. The interpretation of a geometric buried objects depends on operator's expertise and experience (Annan, 1992). In interpreting the radar data, one usually searches for existing anomalies such as hyperbolic reflections, irregularities in largely uniform reflection patterns and changes in the frequency of the GPR signals. Hyperbolic reflections are caused by point reflectors in the ground such as pipes, rocks and voids. Irregularities are usually caused by the disturbances of the natural sedimentation of soil as a result of construction activities. Changes in the frequency of radar signals are caused by changes in the dielectric properties of the transmitting medium; for example, saturation by water lowers the width of 
radar signal (Daniels, 1996). Our field work was planned to be performed every two or four weeks because soil resistivity depends on moisture content. The soil resistivity was measured at each measurement step.

In 26/3/2011, four GPR radargrams were carried out along Trench-1 (1.5 m depth). According to the high quality referred to GPR radargram of $5 \mathrm{~cm}$ trace interval (after processing), the point reflectors and irregularities in reflection patterns corresponded to filled and empty pipes, had moderate to low electrical conductivities, and were believed to be the water pipe and pipe void respectively. These pipes were so difficult to detect owing partly to the absence of hyperbolic reflections. The top of several of them had been hardly picked at a depth of about $1.3 \mathrm{~m}$ because of the 10 " diameter size of these pipes, rather than the pipe's actual $1.5 \mathrm{~m}$ depth (perhaps due to an inaccuracy of the measured radar velocity and soil characterizations), while the other bodies exhibited non-exclusive signs (Fig.5), indicate a slowdown in the radar waves as a result of the natural saturation of the soil. Determining if these signs are related to that body is difficult if we do not know previously the body location underlying earth surface. The soft silty clay soils in the area understudy were strongly affected negatively towards the GPR response; therefore, rock blocks and the empty wooden box (representing weak zones), were difficult to recognize in spite of their large size and own resistivities. In the same day, two GPR profiles were achieved using a $250 \mathrm{MHz}$ antenna along Trench-1 and the same setting and with fully normal water saturation, including two trace intervals 0.3 and $2 \mathrm{~cm}$. The $2 \mathrm{~cm}$ trace interval radargram was interpreted after performing background removal and band pass filtering (Fig. 6).

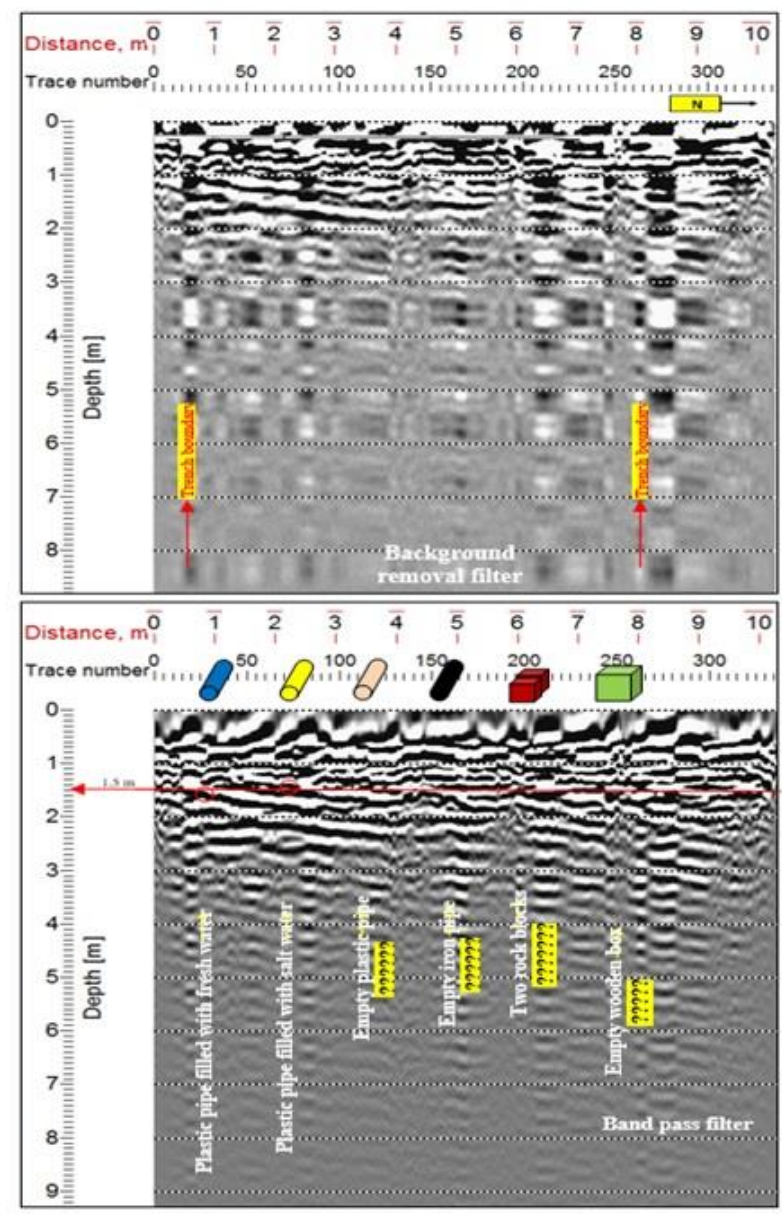

Fig. 5: Interpreted radargrams along Trench-1 with $5 \mathrm{~cm}$ trace interval after processing

Water has highly dielectric constant, thus, radar waves travel more slowly in water saturated ground (Flohrer and Popel, 1996). Here, the saturation condition should be altered inside the trench and 
the soil insitu may wash out. The normal water that was used to saturate Trench-1 positively influenced the media and reduced wave attenuation at shallower depths. The soil of the investigated area was more saturated with fresh-brackish water, the matter that lowers the electrical conductivity of the surroundings of the buried objects and the hyperbolic reflections partly appeared. Two weeks later (10/4/2011), the trench water should be dropped down to the natural water table (around $2 \mathrm{~m}$ ) and the saturation condition should be changed. Thus, another two GPR profiles along Trench-1 were conducted. The most important discovery during this inspection was that the soil may behave more conductive media (due to water saturation) than before and the radar waves cannot propagate or even reach the actual depth of the used antenna; however, radar signals were mostly attenuated due to the wavelet and soil type characterizations. Thus, no object can be recognized in this radargram because the radar waves did not reach 0.8-1.0 m penetrating depth during interpretations (Fig. 7a). Therefore, to obtain some accesses in GPR response, three GPR profiles (250 MHz antenna) were carried out along Trench-2 in 28/4/2011. By increasing the trace interval from $2 \mathrm{~cm}$ to $5 \mathrm{~cm}$, the geometrical bodies can be partly seen, but the plastic pipe filled with fresh water cannot be identified. This finding means that the increase of the trace interval caused less distortion in the radargram. Moreover, the depth of the buried bodies was only $1 \mathrm{~m}$, as shown in (Fig.7b).

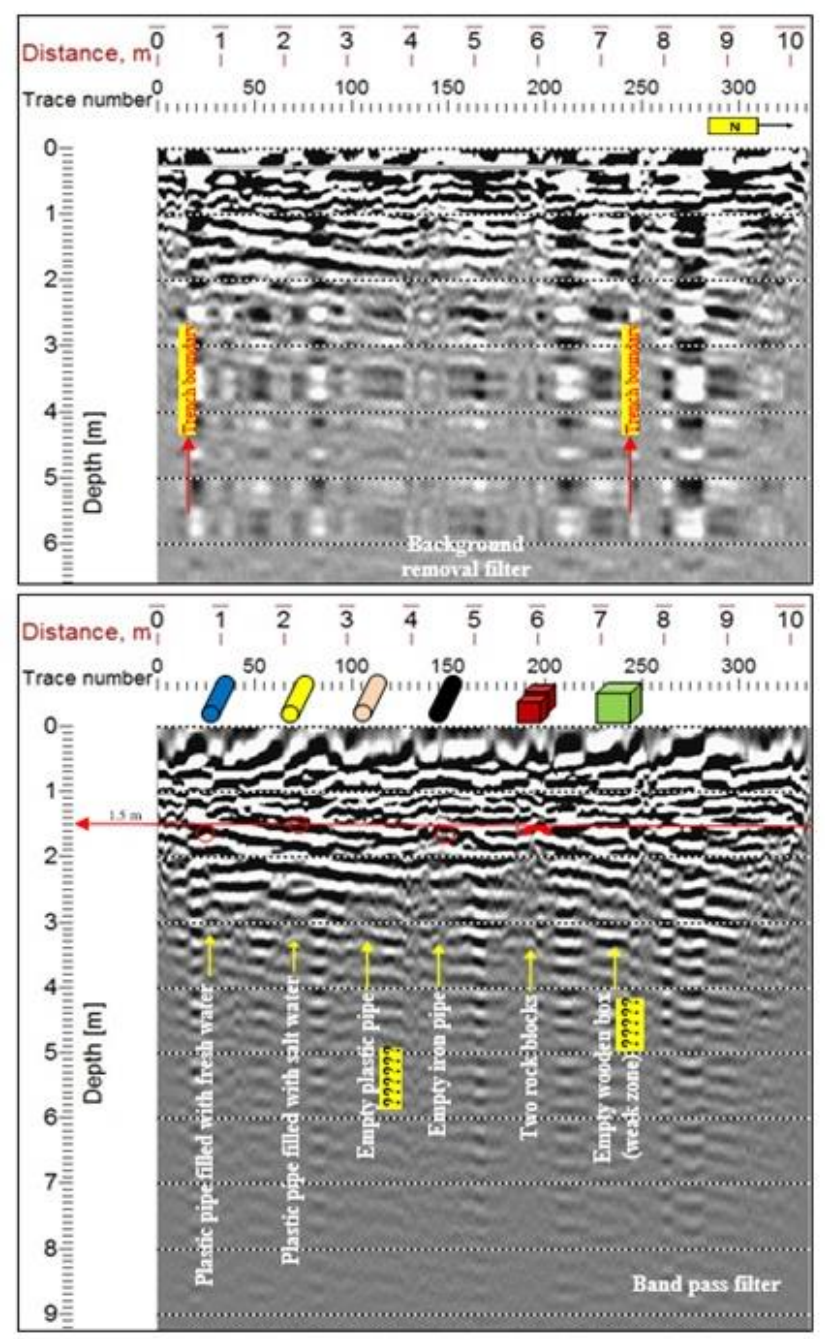

Fig. 6. Interpreted radargram along the saturated Trench-1using $2 \mathrm{~cm}$ trace interval 

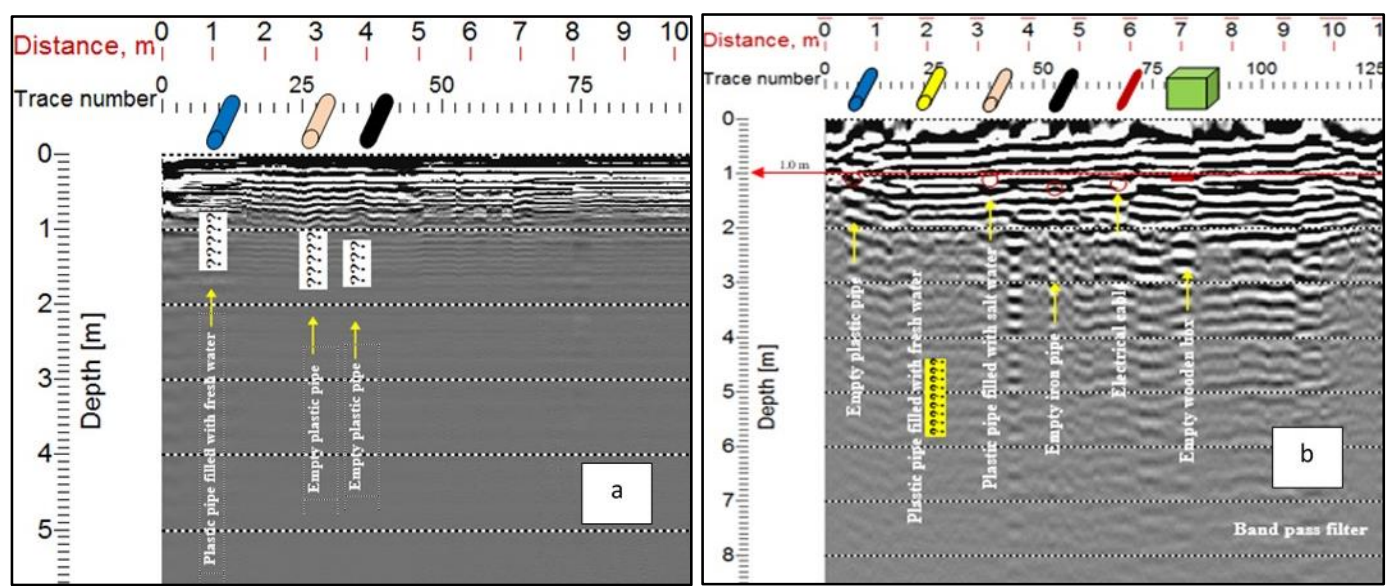

Fig. 7. Interpreted radargram after band pass filter along (a) saturated Trench-1 after 2 weeks and $2 \mathrm{~cm}$ trace interval; (b) Trench-2 with $5 \mathrm{~cm}$ trace intervals

Six GPR profiles (250 MHz antenna) were also performed on the same day (28/4/2011) across the main hole and buried electrical cable near the Geology Department (three profiles for each survey). GPR radargram ( $2 \mathrm{~cm}$ trace interval) was conducted over the main hole with $50 \mathrm{~cm}$ diameter and $2 \mathrm{~m}$ depth, and processed using predictive deconvolution filter in addition to the common filters. This type of filter was used for the first time and it enhanced the signals resolution. The bottom of the main hole extension was predicted and its total depth (about $2 \mathrm{~m}$ ) matched the real depth, but the water level inside hole was at $1.4 \mathrm{~m}$. The GPR profile was on concrete passage way, that is, not along low resistivity soil that caused high attenuation for the radar signal and consequently its penetrating depth.

The depth of the electrical cables was not known in the study area. The main target was to detect the location of the electrical cables buried under the paved road inside the Basrah University in front of the Geology Department. The radargram shows clear signal response owing to this cable. It can be detected very easily by the $250 \mathrm{MHz}$. antenna, the cable seems to be at $1.36 \mathrm{~m}$ depth, and slabs above them were detected at depth of $0.5 \mathrm{~m}$. These slabs were placed in the area to protect cables from heat, pressures and damages. Going back to the Engineering Section, Presidency of Basrah University, no maps available for civil purposes were found; therefore, the detected locations and depths of these cables were given to the Engineering Section for future maintenance. Moreover, the detection of these cables was easier than the previous GPR profiles that run for buried objects (Fig. 8). At the same location of the detected cables, a possible pipe may exist in between at similar depth $1.36 \mathrm{~m}$, but it provided clear hyperbolic reflection. Again, this was another case where the $250 \mathrm{MHz}$ antenna can reach more than 1 $m$ depth. The top low resistivity soil did not exist in this example. The water table was found near this depth because the radar waves disappeared via depth at $1.6 \mathrm{~m}$ (due to signals attenuation).

Two electrical resistivity profiles using Wenner array were surveyed on 26/5/2011 along Trenches 1 and 2. The most important target related to this step was to obtain an idea about the saturation and wettability conditions underlying trenches that might be altered during arid period. During this period, the water table should drop greater than its real depth due to the capillary pressure occurring through the stratigraphic soil column. Based on this fact, the concentration of the dissolved salt within water content existing between the surface and water table probably increased and the soil media was more conductive in which TDS equals to $6790 \mathrm{ppm}$. For the Wenner array, the resistivity sections show a characterized anomaly observed here and there, especially at the beginning measuring points (spacing 1 and $2 \mathrm{~m}$ ) (Fig. 9). Generally, Profiles 1 and 2 still had low electrical resistivity values, because the time and evaporation were not enough to make the soil resistive more than before. The existence of the buried objects underneath trenches apparently did not affect the resistivity anomalies in a large scale except for the 
anomaly observed at the center of the geoelectrical section (belonging to Trench-2). On the same day, four GPR profiles (250 MHz) were conducted, two along Trench-1 and two along Trench-2 using 8 and 16 stacks. Only trace interval was changed from $2 \mathrm{~cm}$ to $5 \mathrm{~cm}$. For Trench-1 where the depth of the buried bodies was $1.5 \mathrm{~m}$, detecting the buried bodies for the $2 \mathrm{~cm}$ trace interval was very difficult.
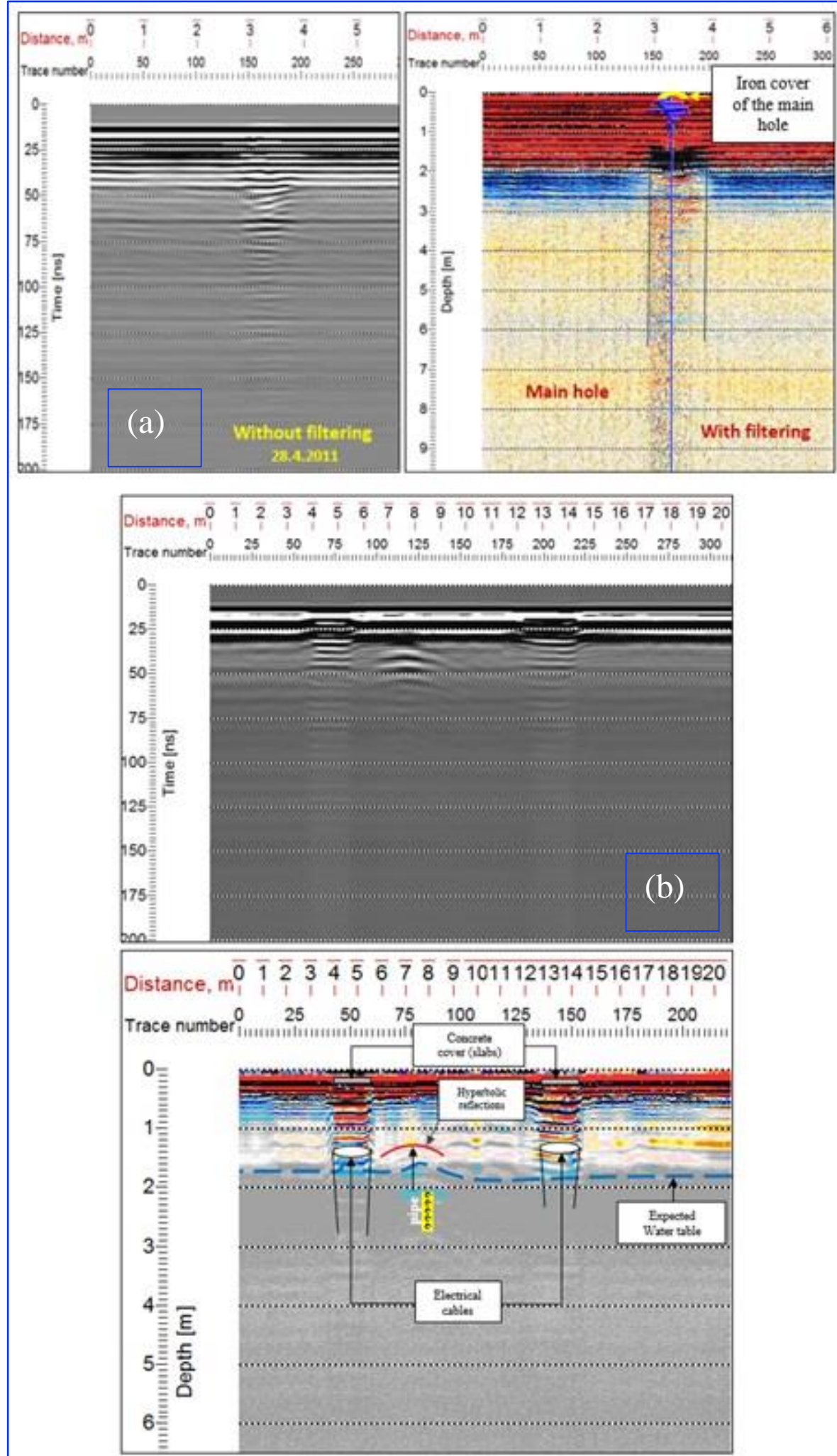

Fig. 8. Interpreted radargrams before and after processing along the main hole (a) and across the electrical cables (b) 


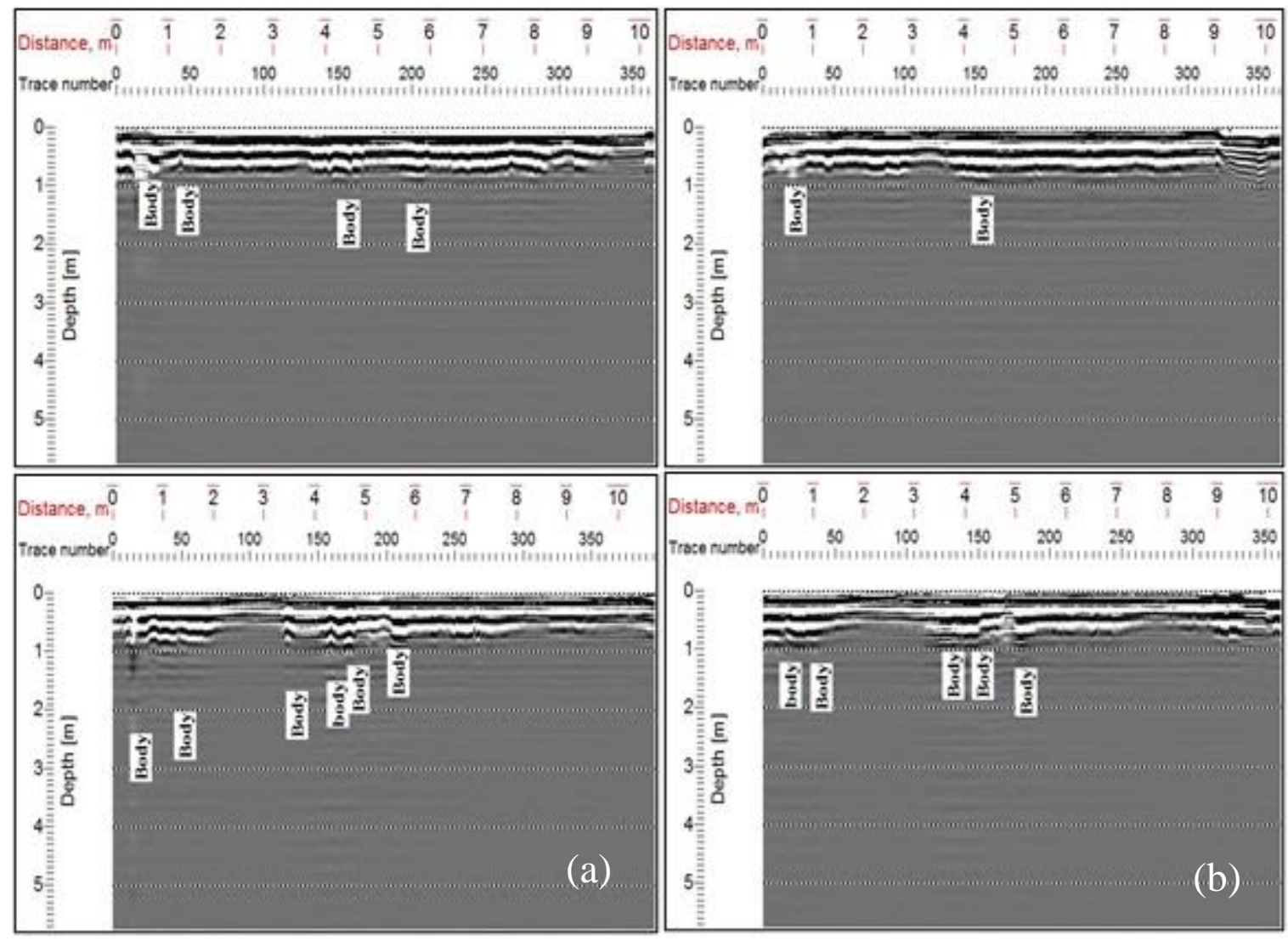

Fig. 9. Radargrams of Trenches 1 (a) and 2 (b) using 2 and $5 \mathrm{~cm}$ trace intervals respectively

The depth of penetration for $250 \mathrm{MHz}$ did not reach $1.5 \mathrm{~m}$. The moisture content of this soil did not change from March to May. The low soil resistivity still attenuated the radar wave. For Trench-2, faint signals may reflect the buried bodies. These signals did not show a clear parabola, which should come out of the normal radar wave reflections. Yet, the $250 \mathrm{MHz}$ antenna frequency showed $1 \mathrm{~m}$ or less penetrating depth for the study area soil. Both trenches radargrams showed a better image for $5 \mathrm{~cm}$ trace interval than $2 \mathrm{~cm}$ trace interval.

On June 6/6/2011, only one point of resistivity was measured near Trench-1. It had a Wenner configuration and for (a) spacing equals to 1,2 and $3 \mathrm{~m}$. Soil resistivity did not change so much. It also showed values less than 2.9 Ohm.m. The soil was still characterized by its high conductivity (Fig. 10). Again, four GPR profiles were done (two for each trench), and no clear signals for the buried bodies were detected in Trench-1. Only signal appeared at the distance between 4 to $5 \mathrm{~m}$ where the iron pipe was buried. Trace intervals of 2 and $5 \mathrm{~cm}$ were employed for this test. For Trench-2, the radargrams showed somehow clear signal for the iron pipe position while no clear signals can be detected for the other bodies (Fig. 11). The soil condition did not change much from March to June. In 26/7/2011, only one point of Wenner array with spacings 1,2 and $3 \mathrm{~m}$ was surveyed parallel to Trench-1. The resistivity values were less than $1.4 \mathrm{Ohm} . \mathrm{m}$. The average resistivity value was still similar to the previous readings probably owing to the brackish-saline groundwater recharge or even regressive plume of the disposal solid wastes that might come from the Geology Department and pollute the groundwater. Thus, TDS determination (9350 ppm) was not real and was neglected. Two additional profiles were taken along both trenches. The radargrams did not show clear signals for Trench-1, whereas, four buried bodies were detected after filtering for Trench-2 (Fig. 12). 


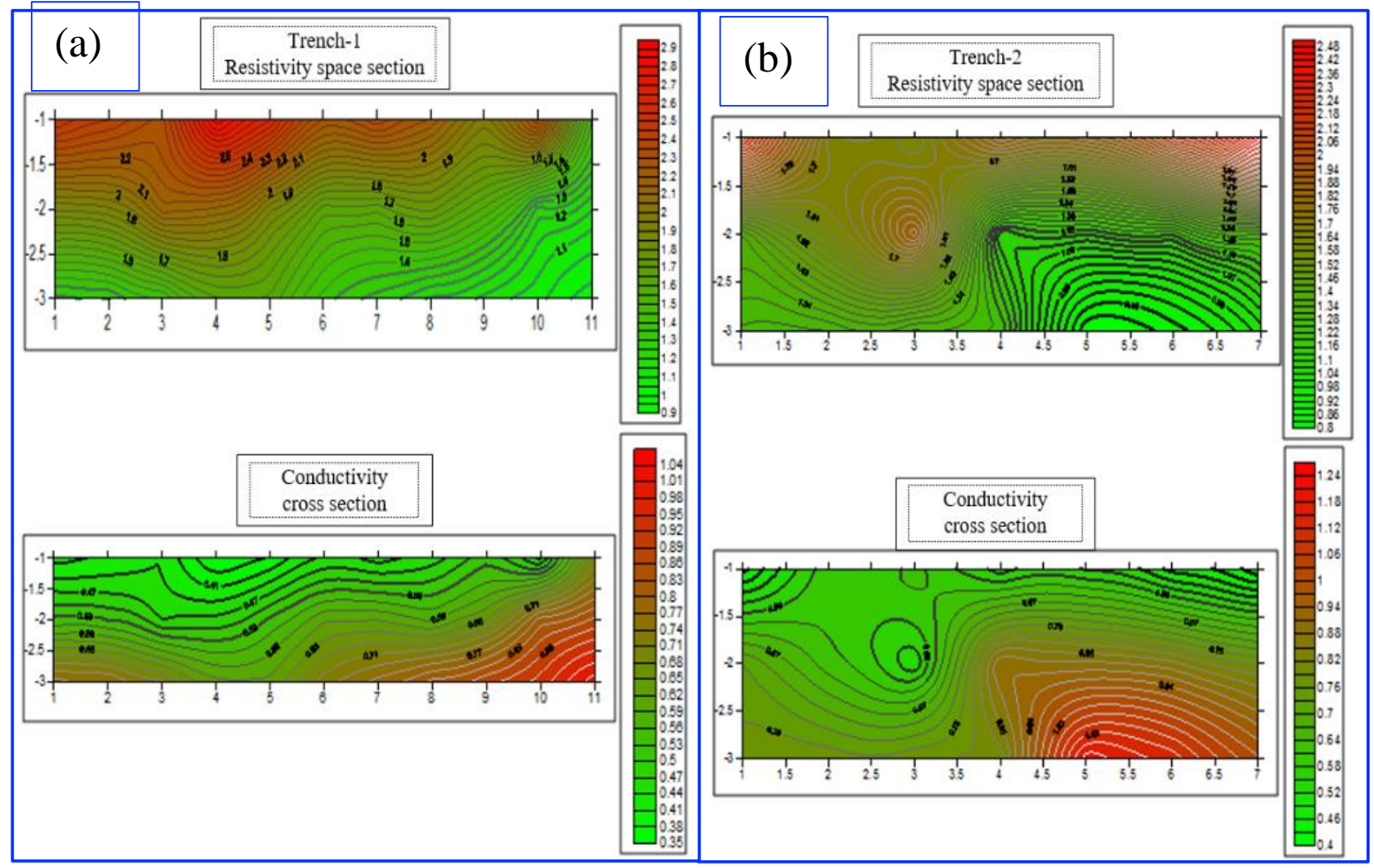

Fig. 10. Distribution of the soil resistivity and conductivity underneath Trench-1 (a) and Trench-2 (b)

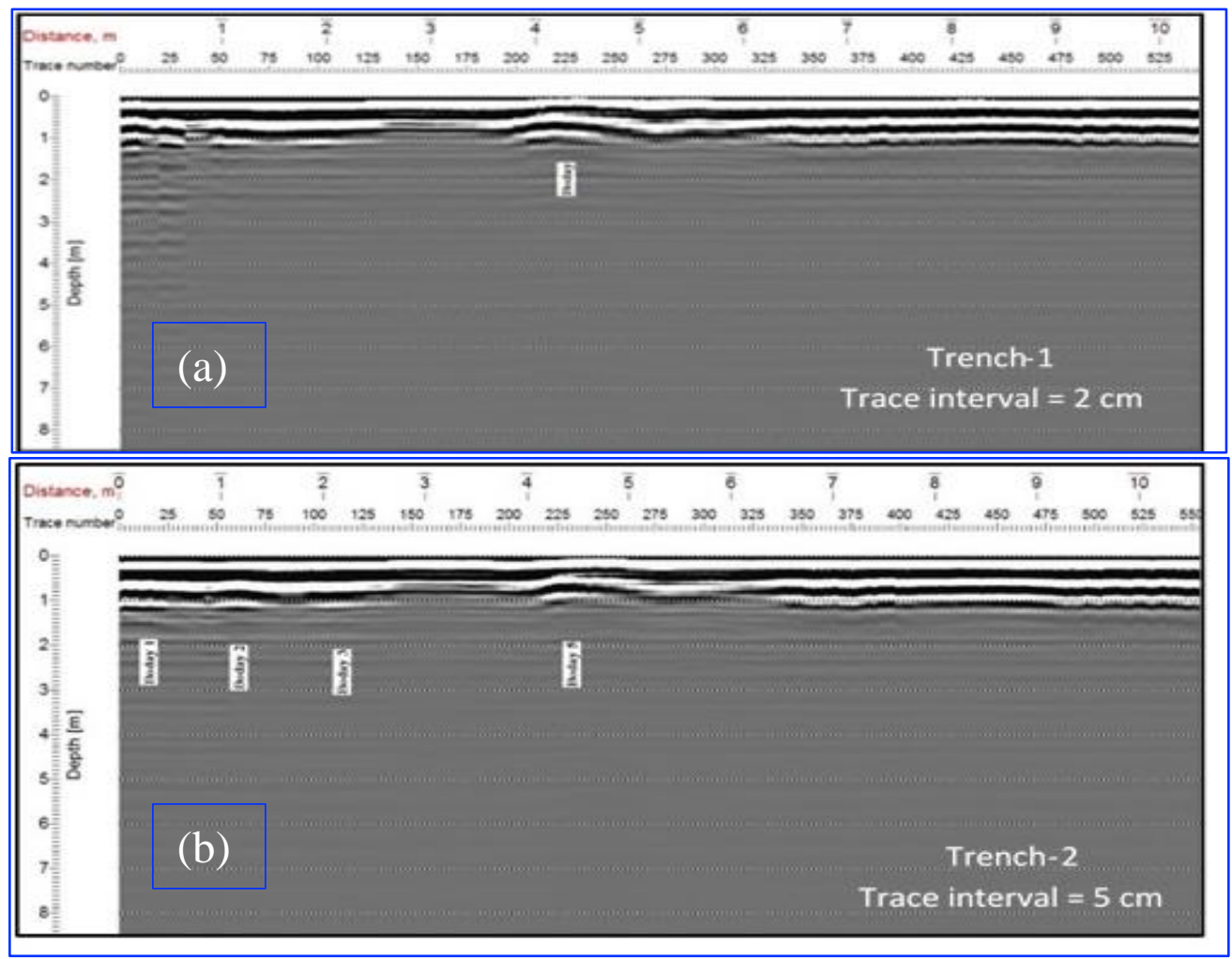

Fig. 11. Trenches 1(a) and 2 (b) radargrams of 2 and $5 \mathrm{~cm}$ trace intervals 


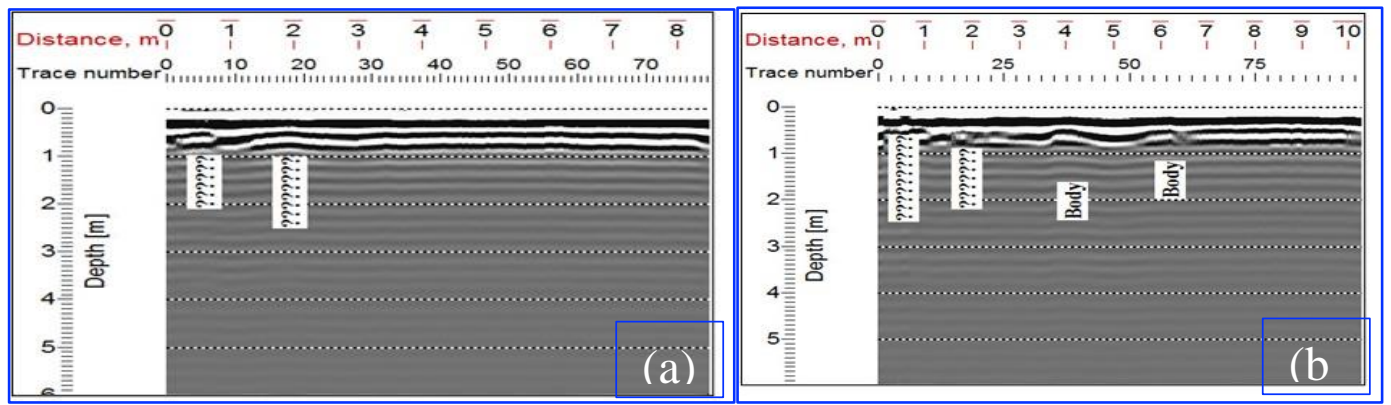

Fig. 12. Radargrams of Trench-1 (a) and Trench-2 (b)

The GPR penetrating depth for the studied soil was still around $1 \mathrm{~m}$ even in hot July. The soil moisture depended on the near surface water table, and the soil itself had a high salt content. On 6/10/2011, soil resistivity was measured prior to this test and found less than $2.94 \mathrm{ohm} . \mathrm{m}$ for Trench-1 and less than $1.4 \mathrm{ohm} . \mathrm{m}$ for places outside the trench. However, six GPR profiles (one for Trench-1 and five for Trench-2) were achieved using 250 and $500 \mathrm{MHz}$ antennas respectively. The GPR settings were changed for the trace interval and time window. The soil at the Trench-1 was washed out during the test of March when it was filled with fresh water. However, the results for this trench also showed no clear signal, but very faint inductions were observed for the existence of the first three bodies, which were not exclusive signals of the GPR. Trench-2 radargram have showed no clear signals too, and the results are nearly negative and unlike those tested in July. This finding is most probably due to salts upward diffusions through summer time. The soil condition of this trench seems to have retrieved its natural condition during summer. This finding made the maximum penetrating depth for the $250 \mathrm{MHz}$ frequency for the natural condition register less than $1 \mathrm{~m}$. The $500 \mathrm{MHz}$ antenna was tested for Trench2 only when the buried bodies were at $1 \mathrm{~m}$ depth. The radargrams showed that the maximum penetrating depth for this frequency did not exceed $0.4 \mathrm{~m}$. On these radargrams, the buried objects locations were represented to show if any relation exists between these locations and the radar signals. The $500 \mathrm{MHz}$ frequency seems not suitable for the studying low resistivity soil (Fig. 13).

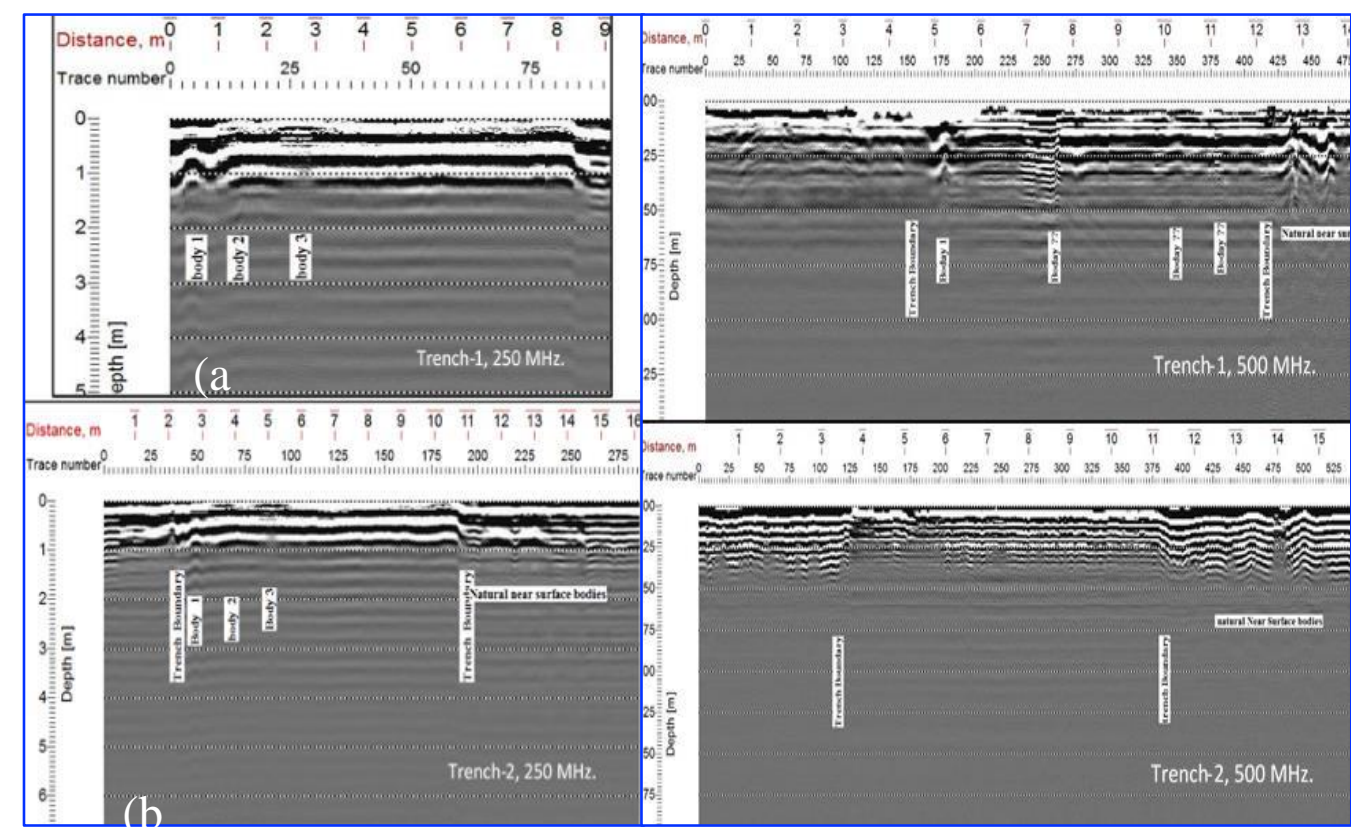

Fig. 13. Radargrams of Trench 1 (a) and 2 (b) using antennas 250 and $500 \mathrm{MHz}$ respectively 
As a result, the area understudy was subjected to continuous alternative different conditions during arid and humid seasons, making the water table always have the same level within the soil and therefore the same water content. Thus, GPR might work here depending on the climate condition. A GPR survey was carried out in front of Basrah Sport City to detect buried pipes, electrical cables and the important optical cable passing through the middle garden or several other places that locate outside this location to construct a bridge across the Basrah-Zubair highway that connects the Sport City with the highway towards Basrah Airport. Therefore, detailed eight GPR profiles were done on 25/10/2012 using 250 and $500 \mathrm{MHz}$ antennas with different settings and filtering. Owing to the silty sand soil of the investigated area, the water table was equals to $2.5-3 \mathrm{~m}$, and from the interpretation of the above GPR profiles, the wave signals that penetrate this type of soil revealed moderate-good GPR sections. GPR sections with $500 \mathrm{MHz}$ antenna, rather than $250 \mathrm{MHz}$ one, are not good for more than $2.5 \mathrm{~m}$. The 250 $\mathrm{MHz}$ antenna provides satisfactory radar sections more than $2.5 \mathrm{~m}$ and hyperbolic reflections, related to the clear buried bodies. The pipes filled with water, cables and weak zones were easily extracted from the radar sections during the above surveys using $250 \mathrm{MHz}$ frequency antenna. Moreover, the exact locations of these bodies were checked by the direct observations, available maps or even drilling. These encouraging results became available perhaps due to the enhancing happened to the signal penetrating (less radar attenuation). The interpreted GPR sections for several profiles are shown in (Fig. 14). The important optical cable may not exist inside the middle garden.

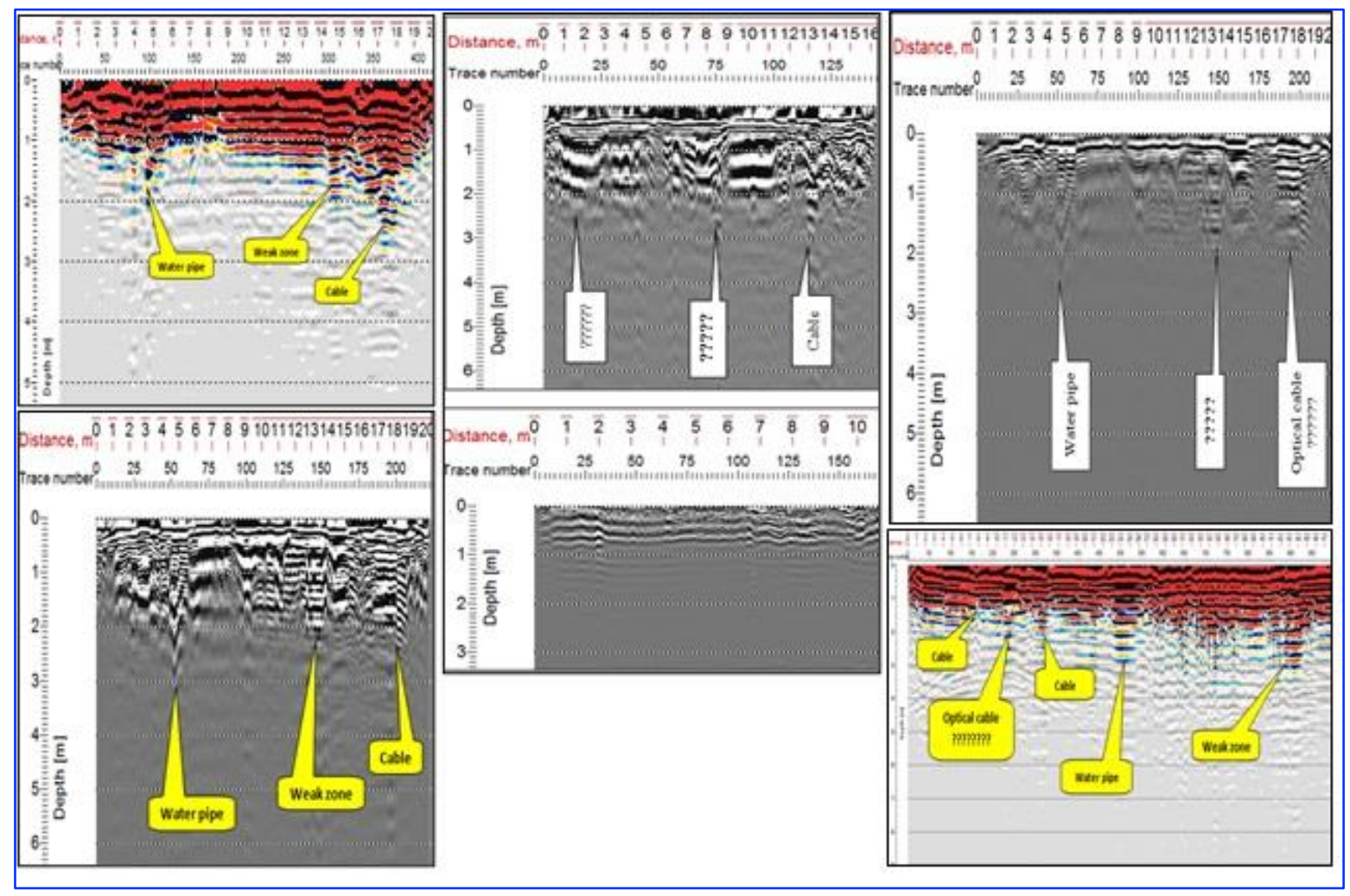

Fig. 14. Radargrams of profiles, 2 and 4 with antenna of 250 (a) and $500 \mathrm{MHz}$ (b) using 5 and $3 \mathrm{~cm}$ point intervals for each antenna respectively

\section{Conclusions}

The resistivity surveys using Schlumberger array (VES) or even Wenner array (horizontal profiling) inside Basrah University provide very low resistivity values owing to the water content and high salt concentration of the soil. The GPR method does not exceed $1 \mathrm{~m}$ depth inside the university clayey silt soil because of the high absorption of EM waves within the salty layers at the two trenches 
constructed to test the GPR method. The soil resistivity has values of less than 3 Ohm.m in March 2011. Thus, the depth of penetrating for the ground radar at Basrah soil mainly depends on the soil conditions, particularly the resistivity of the soil. The GPR and resistivity tests for the two experimental trenches suggest that the climatic conditions from spring times to autumn times have a minimal effect on soil resistivity. Consequently, the GPR test results for the buried objects at the two trenches show almost the same results. By contrast, salinity increase more in October, which means that the upward salt diffusion occurs in the hot summer. The water table at the study site is neither influenced by neither the hot season nor moisture content.

The GPR (of $250 \mathrm{MHz}$ ) tests results for the buried objects at Trench-1 of $1.5 \mathrm{~m}$ depth hardly showed the locations of these bodies despite using different types of filters. Filters cannot solve the problem in the absence of genuine radar reflected signals. The GPR results for the buried objects at Trench-2 of $1 \mathrm{~m}$ depth shown several indications on the locations of the bodies, particularly at the beginning of the experiment when the fresh water was used to fill the trench. Thus, the maximum depth for the GPR method $(250 \mathrm{MHz})$ at the salty soil with a resistivity was less than $3 \mathrm{Ohm} . \mathrm{m}$ is less than 1 $\mathrm{m}$. The GPR signals can be detected by using the filters. The GPR tests at the paved road and concrete slabs detected the buried objects at $2 \mathrm{~m}$ at Basrah University using $250 \mathrm{MHz}$ antenna. The GPR can reach a depth of more than $2 \mathrm{~m}$ when the top surface layer has no low resistivity. Therefore, it can be used to detect the underground pipes and cables beneath the buildings and roads of depth less than $2 \mathrm{~m}$. The GPR tests with $500 \mathrm{MHz}$ frequency show very limited penetrating depth for the low resistivity soil (less than 3 Ohm.m). It is not more than $0.40 \mathrm{~m}$. No radar signals are detected in the test for the two trenches. However, in Basrah Sport City, the matter is different, the region certainly, is less conductive and GPR signals move forward within the ground at a depth of approximately $2.5 \mathrm{~m}$.

\section{Recommendations}

- In this study, the GPR limitation for the part of Basrah soil is studied and should be considered for any future use of this method. The resistivity of the soil should be measured before any GPR work. In high-conductivity soil, the GPR method is not considered suitable for the exploration of 250 and $500 \mathrm{MHz}$ GPR frequencies.

- The GPR method with low frequency (50 MHz or less) must be tested for low-resistivity soil.

- The GPR method must be tested during the winter season and after heavy rain, which could wash out the salinity of the top soil. The positive results of such test could help in exploring that parts of Basrah area with low-resistivity soil.

- Using filters with no real radar signals can easily result in a misleading image. The radar that reflects signals should be checked first before using any filter.

\section{Acknowledgements}

The Iraqi Ministry of Higher Education and Scientific Research is gratefully acknowledged for their endless supports during our research and our thanks going to the chief of the Al-Anwar Soura General Company to permit us for doing our GPR field work in Basrah Sport City. Also, we would like to thank Dr. Raed Aziz, Dr. Wala'a M. Khudher and Dr. Haider H. Faraj for their cooperations and field assistance in resistivity and GPR surveys. The authors are very grateful to the Editor in Chief Prof. Dr. Salih M. Awadh, the Secretary of Journal Mr. Samir R. Hijab. and the Technical Editors for their great efforts and valuable comments.

\section{References}

Abed, A.M., Thabit, J.M. and Al-Menshed, F.H., 2021. An Attempt to Image Um El-Adam Cavity Structure in the Karst Terrain at Hit Area, Western Iraq. The Iraqi Geological Journal, 54 (1A), 44-54. 
Al-Khersan, E. H. 2012A. VES and GPR investigations to delineate buried objects, cavities and weak zones inside an oil establishment southern Iraq, with the assistance of hydrogeological and geotechnical information, Yanbu Journal of Engineering and Science, 7, 75-88.

Al-Khersan, E. H. 2012B. Geoelectric monitoring of saline water intrusion in Dibdibba aquifer at Zubair-Safwan area, southern Iraq, Marsh Bulletin, 7(1), 48-62.

Annan, A. P. 1992. Ground penetrating radar: workshop notes, sensors and software inc.: Mississauga, Ontario. 246.

Compagnie générale de géophysique, 1963. Corporate author: contributor: European Association of Related Work: master curves for electrical sounding, EAEG.

Daniels, D. J. 1996. Surface penetrating radar, OCLC Number, 35950135, Institution of Electrical Engineers, London, UK., 300 pp.

Flohrer, C., Popel, M. 1996. Combination of a Covermeter with a GPR-system: a tool for detecting prestressed bars in concrete structure. proceedings $6^{\text {th }}$ international Conference on ground penetrating radar, Department of Geoscience and Technology, Tohoku University, Sendai, Japan, 273-277.

Gómez-Ortiz, D., Martín-Crespo, T., Martín-Velázquez, S., Martínez-Pagán, P., Higueras, H. and Manzano, M. 2010. Application of ground penetrating radar to delineate clay layers in wetlands. a case study in the Soto Grande and Soto Chico watercourses, Doñana SW Spain, Journal of Applied Geophysics 72, 107-113.

Haddad, R. H., Hawa, AJ. 1979. Hydrogeology of the Safwan Area, South Iraq, Scientific Research Foundations, Baghdad, Iraq, 323.

Khorshid, S. Z., Al-Khersan, E. H., Al-Kashan, Z. 2006. P and s-waves evaluation for engineering site investigation at a hostel complex inside Basrah University, southern Iraq, Basrah Journal of Science (a), 24 (2), 27-37.

Mahmood, R. A. 1997. Study of some Geotechnical Properties of Quaternary Deposits in Basrah City. M.Sc. thesis, College of Science, Basrah University, (unpublished), (in Arabic), 115.

Orellana, T., Mooney, H. M. 1966. Master table and curves for vertical electrical sounding over layered structures. interciesnecia: Costanilla de los Angeles, 15, Madrid, Spain.

Telford, W. M., Geldart, L. P., Sheriff, R. E. 1990. Applied Geophysics. Cambridge University Press. England, 147 pp. 